\title{
New ways of interacting with culture consumers through cultural services marketing using Big Data and IoT
}

\author{
Andrei L. BĂDIN \\ The Bucharest University of Economic Studies, Bucharest, Romania \\ andrei.badin@mk.ase.ro
}

\begin{abstract}
This paper presents the definition of cultural marketing services phenomena, trying to identify new ways to interact and gain insight in consumer preference and behavior. The existence of Big Data and Internet of Things can be used in the Cultural Services sector. Traditional marketing and digital marketing can be reunited with the help of Big Data trends and analytics to better connect with target audience. Big Data can be used to analyze and discover new patterns in social trends and uncover customer preference. There are digital ways in which now consumers interact with their favorite cultural service and these are mostly, by internet. This new level of interaction live with your favorite cultural service, band or artist, even with other services like museums or conferences, where a human voice exists, can make the difference between returning or not to a certain service. Customizing the experience for each customer gives way to improving the overall marketing mix and improve profits. Big Data can help at improving this experience and create a better hypothesis for future strategies used in new cultural events. The main objective of marketing cultural services is to offer the client a unique selling proposition that can't be refused. Using the internet, they leave a digital footprint with every action they make in regard with a certain services: they engage via social networks or check in via GPS. These are just a few examples of raw data that can be collected and used to exemplify future possibilities and predict where people will be in relation with a certain cultural call to action. This information, with consumer behavior studies, motivations, drives and other characteristics (age, sex, income, social position) can determine the best marketing approach for a certain event or communication in order to achieve maximum return on investment.
\end{abstract}

Keywords: Big Data, marketing services, marketing mix, Internet of Things, cultural services.

\section{Introduction}

The hypothesis is that culture consumption is on the rise and a very helpful instrument that adds to this is the use of the internet. The development of the digital environment can be seen as a threat or as an advantage to companies that promote and sell cultural services and products. This can be used in their interest and it can only be used as such by seeing how it works.

In 2017 there is a very high returning interest in arts and culture. There are many funds from the European Union that help E.U. countries in developing and evolving the culture level of consumers. The cultural activities that are statistically analyzed by the E.U. are literature awareness, free time activities like attending live performances, seeing movies at the cinema and visiting historical and cultural land marks (Culture Statistics, 2016). We can see from these statistics that culture consumption is on a slow and steady growth path, even if there are some exceptions. We can see that the trend for attending live cultural performances between 2007-2011 where not on the positive side for Cyprus and Romania, but it as for the cinema. It is understandable that some countries excel in some areas of culture participation. Another important variable is the differences between categories of educational background for the people that took part in the study over a 12 months period. One conclusion that we can take from this is that in 14 out of 20 countries 
members of the E.U. is that there is a positive trend throughout all cultural participation events (reading books, active participation at theater, museums and visiting important land marks). For reading books for example, one of the most visible impact of higher education exercised over reading habits is in Romania and in Luxembourg the smallest. Further down, the analysis of culture consumption in Romania will be made on the basis of research made by the National Institute of Statistics (INS) for the years 2014, 2015 and 2016.

PICBE | 94

Seeing the tendencies on an E.U. level, we also have to explore the digital environment development throughout 2016 and 2017. For the year 2018 we know that the General Data Protection Regulation (GDPR) is to produce effects in May of 2018. One positive consequence of this normal tendency to protect consumer personal data is that in this way clients and potential clients will be more empowered and trusting in giving their personal data in order to complete relevant questionnaires on preferences and ways of consumption.

Big Data and Internet of Things (IoT) are one of the most important breakthroughs of the $21^{\text {st }}$ century. We have the power to process high volumes of data and obtain patterns in order to improve life of citizens, increase efficiency for companies that work with high quantities of data and give a better experience to consumers. Big Data can be used in smart cities, Barcelona is one of the smartest cities in the world and it uses SAP, a technology that analyses data even from the levels of garbage in trash cans and reroutes garbage trucks on the go in order to save fuel. This power of processing can be used in the performing arts and culture consumption seeing that most books and newspapers are now read online, museums and important cultural sites around the world can be visited virtually and even live performing arts are being broadcasted on the web. All of this data is connected with social media and can be quantified in order to predict new trends and establish base lines for culture consumption in a given time period. Mathematical algorithms are already in place in social media that help giving people the best deal on what products or services they searched for and even offer suggestions for future acquisitions.

\section{Literature review}

\section{Cultural consumption}

From the National Institute of Statistics of Romania (INS, 2016) (INS, 2017) we can see in the reports for 2014, 2015 and 2016 that cultural consumption, the same areas explored by the E.U., is in some cases in a growing trend. Part of this analysis will be made on the elements explored by the E.U. and INS, and these are as follows: public libraries, museums and public collections, the activity of arts companies, books and newspapers and cinematography, radio and television.

In the analysis that follows we will highlight the trends of culture consumption in Romania. From these trends we could extrapolate further in seeing the causes for each trend from year to year. There are also other reasons for a decrease or increase of a certain population in a certain domain: region, access to education, development of cities and interests.

The public libraries in 2015 reached a number of 10.111 units, a number that decreased since 2014 with 734 units. The university libraries have diminished as well by 2 since 2014 and now there are a number of 101 university libraries. The overall trend is going downwards according to INS statistics. The number of people that used libraries are 
also lower in 2015 than 2014 by 6\% (227.000 people). As a trend for 2015 and 2016, libraries have offered in average 11 volumes for each customer (INS, 2017).

The museums and public collections are on an ascending trend, seeing that in 2014 many museums that were closed, have opened in 2015. We have over 431 units (390 museums, 6 monuments, 21 zoo's, aquariums and botanical gardens, 14 natural reservations). The number of visitors for these attractions are on a descending trend by 20, $6 \%$ in 2015 by comparison with 2014 where we had over 15 million visitors. The number of visitors remains the same in 2016, over 14 million people visited museums and public collections (INS 2017).

The activity of arts companies is on a growing trend since 2014, following through 2015 and 2016. The number of companies in 2015 was 254. Even if the number of spectators has lowered from 2014 to 2015 by 7\%, the overall statistics for art companies have increased: number of institutions, concerts and events, representations and places in theaters and other locations for art production. As an average of participants there were 292 out of 1000 in the year 2015 at art shows and any other form of cultural shows. There were over 22.000 representations in 2016 and over 5, 7 million spectators (INS, 2017). This trend is positive, even though the 7\% decrease in spectators is connected to the fact that since 2014 the paradigm of arts and culture has shifted into a more established niche stand-up comedy and small theater groups. This is an apparent decrease in interest, but if we look at all the other statistics we can see an improvement in culture infrastructure and even interest.

The activity of books and newspapers are growing, since 2014 to 2015 the number of publishers has increased by 111 units, achieving 576 units in 2015, and reaching 558 units in 2016. Even with this increase of publishers we can see that in 2015 the number of papers printed has lowered by 15 million. In 2016 the downward trend continued mainly due to the shift in books and papers reading culture, more people are reading online because more publishers, journalists and writers are going digital with their work.

The activity of cinematography and radio/television can be as well look at through the lenses of shifting digital paradigm, adopting the internet as a channel of communication. In 2016 we see an increase from 82 units in 2015, to 92 cinematographic units and 13 million spectators.

We can see that the main trend is of slight growth and improvement of cultural events and arts. The new digital trend and use of internet is used for culture as well. We have in 2016 data for the year 2014 about individuals in the E.U. using the internet for cultural purposes: $67 \%$ of individuals used the internet in order to read magazines, books or newspapers, $51 \%$ used it to watch movies or listen to music and $31 \%$ to listen to radio. Furthermore over $56 \%$ of individuals use the internet to have access to knowledge tools (Culture Statistics, 2016). Seeing this data for the year 2014, we can only expect a growing trend for the internet and its use in cultural purposes seeing that in 2017 many theaters broadcast live its performances and Andre Rieu did the same thing with the cinema when he had a show in Germany in 2016.

The biggest growth is seen in the use of internet in order to purchase cultural goods and services. From 2010 to 2015 (positive trend) we can see that $23 \%$ of people at E.U. level are buying these things, and the trend is steadily increasing seeing that many arts and culture companies are moving in the digital environment. 
Having this picture of trends in cultural consumer goods and services in Romania and the use of internet in the E.U. we can attempt to extrapolate the information gathered and see how it can be improved with the help of the marketing services mix, digital marketing and Big Data.

\section{Marketing services mix and digital marketing}

One term that can help in the analysis of cultural services, consumer engagement, consumer satisfaction and the use of the internet is "convergence". Convergence means the coming together of previously separate industries and product categories (Keegan and Green, 2017, p. 493). This term is used in according to any business that uses the know-how of another business to function, for example, tourism and gastronomy: there are many tourism companies that promise a gastronomy tour of a country. For the digital example we can see that at one moment in time the businesses that were on the internet were occupied only with providing services and goods at lower prices than companies that had physical shops. Interdisciplinary exploration is used in order to create a better user experience for the potential customer, adding experience from computer science, human science and machinelearning (Kelliher, 2015). Companies that made artistic services for the public were working in theaters with actors and managers that had the job to sell the play or concert. Now these companies are on the internet, selling. All business sectors are on the internet, seeing the importance of a presence established here and promising potential customers a unique experience if they buy their product or service. One example of convergence is that Alibaba, an online shop in China, has more than 600 million registered users and at least 100 million are shopping everyday (Keegan and Green, 2017, p. 494).

Convergence is a term that can be used easily alongside "digitization" in order to complete the environment that cultural activities can function in. The term digitization means a mass adoption of digital technologies and applications by consumers, companies and governments and are connected with each other (Grone and Acker, 2015, p. 6).

The statistics on culture participation and growth presented above show, in most cases, stagnation and even decrease in the non-digital part of the cultural business, but, as we can see in this digital case study of the E.U. we can see that the digital side is growing steadily from year to year with $1.2 \%$ each year since 2003 (Grone and Acker, 2015, p. 7). Consumers are willing to pay for cultural and arts content even more now than in the past ten years.

The marketing services mix is based on product price, place, promotion and people (Kotler, 2011). Even though the service mix of 7 elements: product, place, price, promotion, process, people, physical evidence, can be used, in order to simplify the concept we will be using the 5 elements. The most important step in creating an improved and pro digital environment marketing mix is to analyze the way in which it works. Using the internet can alter the marketing mix and each element can have an impact on each element of the mix (Chaffey and Ellis-Chadwick, 2016, p. 250). The impact of the internet on the marketing mix can have positive impact in the way in which the marketing strategy is created with the help of digital tools like social media and campaign testing. The digital environment can offer the possibility to explore new product placements, pricing tests, creating new segments of consumers and have a better understanding of consumer needs and motivations. 
By means of product or services we can understand the good that will be bought by a consumer at a given time. The cultural service, in this case, can be modified to answer specific needs of the targeted segment and programmed to answer the given need at a time that the company sees fit through research, interviews and questionnaires. Of course, by this mean, consumer behavior is needed to be taken into consideration (Chaffey and EllisChadwick, 2016, p. 261).

PICBE $\mid 97$

When we talk about price we understand the level which a consumer is willing to pay for a product or service in order to satisfy his necessities. With the help of the internet and digital tools we can test the pricing. Dynamic pricing means that new customers can be given discounts in order to gain loyalty (Chaffey and Ellis-Chadwick, 2016, p. 275). Pricing in the creative arts cannot be a factor that defines the service or product. People will pay the emotional price in order to gain satisfaction and if their expectations are surpassed then they will become loyal to the brand or company.

The place where the actual payment is met can be a physical one or through the internet. The most important step in adopting a pro digital marketing approach is that the relation with the customer can be unique by customizing each step that the customer has to make in order to get the product or service they are looking for. Payment mechanism are evolving as well so that the consumer feels safe in purchasing online.

The promotion in the online environment can be used by communicating with the targeted segment and be able to have even instant feedback. There are many communications tools that can be used, advertising through Google's AdSense, create call to actions that make the potential customer buy or accomplish another sort of conversion set up by the advertiser, direct email, questionnaires and even social media posts. A complementary service could be the call-back facility or online chat, where the consumer gets the chance to ask questions and receive feedback from a real human being, or give feedback on any action he made (Chaffey and Ellis Chadwick, 2016, p. 286).

The people in online are used to keep the interface of communication with the segment of consumers up to date and be relevant with information in order to satisfy or even create new needs for them. Support is very important in the digital space and this can ensure interaction on the go with potential customers that can be convinced into buying or even promoting the service without being rewarded, just by answering the needs and satisfying them fully. The customer satisfaction needs to be very high in order to achieve brand followers.

\section{Creative arts in the digital environment - social media and consumer behavior}

Digitization has made it possible for creators to work from different parts of the world in order to create a uniform piece of art without interacting in the real world. This process has also permitted the creator of cultural content to be closer to the consumer, listen to his demands and offer specific services for his needs. The creative material that is achieved is much broader because every consumer can become part of the creation, this means that consumers can become, at a time, creators. As time goes by, consumers become much more sophisticated and engaged, thus raising the stakes in any sort of product or service creation process (Grone and Acker, 2015, p. 33).

Another approach to digitizing content is the digitizing of museums and one of them is the Metropolitan Museum of Art in New York. The aim of this is to better preserve 
artwork and engaging new audiences from Europe, Asia, Australia, South America and Canada. The innovative approach helps by enriching the user experience and enables an interactive consumer experience. This helps museums be more digitally aware and benefit from social media platforms like Facebook, YouTube, Instagram and Twitter. (Barnao, 2017)

The Tate in London generates revenue from digital initiatives and products. The Tate has managed to create a digital community with the help of social media and blogs. This helps engage with potential consumers and give the possibility to offer access to the gallery. One use is for educating students and another can be creating fundraisers with the help of its platforms for repair or maintenance of different museums in the country (Grone and Acker, 2015, p.62-67).

This new model offers new ways to realize products and services, implement strategies that keep in mind the fact that they are not permanent, but can change from day to day. The creative industries can outstand trends that society creates and the digital ecosystem can help it thrive. Cultural differences can offer companies unique selling propositions that can be used in order to target new segments of consumers from other parts of the world. Each element of the marketing mix will be adapted for each segment of consumers in the country that will be targeted because of cultural differences. Consumer behavior is different from country to country and expectations can vary (Blythe, 2005, p 330).

The consumer profile has variables that can be discovered through social media or by creating a platform from which consumers can engage with the company. Some of these variables are extremely important in order to achieve the established conversions of the company such as: education (this element can say a lot about the way in which the consumer uses the internet and what the company can expect from him), employment (how much and what services the consumer can buy), geography (cultural differences can be used in order to engage the consumer in other ways, Asia has the most internet users and this can be used in campaigns), mobility (how people shop online, when they shop and what they look for) (Chaffey and Ellis-Chadwick, 2016, p. 624).

Companies cannot appeal to all buyers in the same way because they are unique and each one of them has different expectations on their needs. Companies must identify and design customer centric strategies that build long lasting relationships with customers (Kotler \& Armstrong, 2017, p. 213).

Companies that promote culture and fine arts should respond in the same manner as big companies comply with company social responsibility (CSR) campaigns in order to attract attention to certain parts of society's negative elements and improve them. The corporate cultural responsibility (CCR) approaches a different vision which helps the company balance out conventional cultural activities or challenging ones by means of long or short term objectives. CCR can be implemented as well in the companies that benefit from having multicultural employees and more so for those that target multicultural markets. (Cejudo and Rodriguez, 2016).

Consumer behavior is very important when a company chooses a certain marketing strategy for the creative arts industry. Before making any plan, the company must understand fully their consumers and their buying habits. Analyzing their profiles from an economic and demographic point of view gives insight into the market. The marketing 
strategy must be made by knowing the consumer. By knowing the consumer we refer to an analysis of cultural, social, personal and psychological factors that should be taken into consideration because they determine the level of satisfaction the consumer expects. This analysis can be made with the help of questionnaires and the study of the digital social behavior. When a consumer considers buying a certain service they recognize a certain need, they search for information and see what other alternatives they have and after that they decide on whether to buy it or not. After the acquisition, if the company met the consumer's expectations, that level of satisfaction will make the customer repeat the experience and even promote that level of satisfaction to his social group. (Jimenes and Gervilla, 2011, p. 142).

\section{Big Data and Internet of Things}

There is an abundance of information that exists in the online environment. The most important part is that this information is made public by consumers on their social media. This can be used to benefit the relationship between company and client. For the consumers that are interested in acquiring services in the performing arts and cultural events industry have a potential to be targeted with specific campaigns. The potential consumers of arts and culture have a specific profile that fits a certain marketing approach. The strategy is used to attain new market segments or supplement existing ones with new potential clients. (Behnam, R., Arabghalizi, T. \& Brambilla, 2017).

Big Data is used to define the massive volume of digital data comprised of human activity and is impossible to process with existent data analysis tools. The Gartner Group`s definition of Big Data is the 3 Vs, and they refer to: volume, as in quantity of data, structured and unstructured; variety, as in the fact that data can be in all sorts of shapes and sizes, images, databases and digital streams; velocity, as in the fact that Big Data sets are in a continuous move and expand in real time (Bowman et all, 2017, p. 287).

The content published by people on their social media and the online context offers ample material for campaign and strategy construction in order to enrich the digital marketing experience of potential customers. This allows companies to create more indepth and unique experience for every customer (Papadopoulos et al, 2015, p. 3).

One industry in which digitization has had a very interesting impact is the music industry. Consumers here range from segment to segment because music genre are so many. It would be counterintuitive to say that material music sales like cd`s, dvd`s or vinyl have gone up seeing the digital trend and how people consumption behavior is right now. The acquiring of music is very easy, one click and the music you want is downloaded. Also, in this industry, there is also impulse buying. One interesting fact about the music industry is that the digitalization of music material has generated consumer demand on material items like cd`s, dvd's and even vinyl's. This example shows that the digital environment helps the development of non-digital and traditional ways of doing business, even revamping lost forms of art or culture representations, bringing them forwards in the $21^{\text {st }}$ century, like the vinyl (Maaudda, 2011 ,pp. 32-34).

The arts and culture companies have been slower than other companies from other industries to enter this step of digital readiness. More and more companies collect and use data gathered from consumers and campaigns in order to create a more connected and responsive organism that functions by measuring impact (of profit and non-profit cultural 
and artistic events) (Moore, 2016, pp. 104-115). The impact can be measured with the help of "noise" from social media and press reaction.

Large quantities of data can be stored in cloud. At the moment, the cloud can be used not just to store, but to process at high speeds massive volumes of information and data. One proposal is to use an application that stores the users input data and automatically creates patterns for the consumer and facilitates access to relevant and personalized information. This application can function with a user name and password, granting the only the consumer access to his information. Of course, large quantities of data can be extrapolated and used to identify large pattern tendencies to preemptively meet market demands. This application can help consumers by offering them live information (new services, new products, if they give their location they can benefit from seeing the closest activities/products to him or get the best deal time/money). (Ourasang, G. and Parande, P., 2016, pp 2-4).

The internet of things functions with big data. Fog computing is a concept proposed by Cisco in 2014 that addresses the paradigm that not all applications and services fit well with the digital stream of data: video conferencing, geo-distributed applications, fast mobile applications and large scale control systems. Fog computing exists in order to serve the demands of different working applications in the context of internet of things (Arkian et al., p. 154, 2017). One example for a smart city that communicates with local businesses can be that of discovering consumer interaction in a park and generating possible opportunities to engage in different cultural services, theater or shows, which are in the near vicinity. This can help predictions made for city organized events: marathons or fundraisers.

\section{Methodology}

One of the methodology used in this paper is literature review in which I surveyed latest articles in the service marketing and big data domain in order to extract the most important trends and realize connections between these trends and sets of data. The other methodology used was of a quantitative measure of data offered by the National Institute of Statistics in Romania and European Union that measured culture active participation by countries and finally in Romania. These sets of data have been analyzed in a direct way with the specialty literature in the domain of digital marketing, cultural services marketing and Big Data in order to obtain trends and possible viable applications for advertising and mobile marketing.

\section{Results and discussions}

The findings presented in this article are of a practical nature. By analyzing the data sets obtained from the E.U. cultural consumption report of 2016 and INS data from 2014 to 2017, together with the latest trends in service marketing, digital marketing, big data and the arts and culture industry, we could draw the conclusion that culture consumption is not very easily quantifiable. Although culture consumption is stagnating in some areas like cinema or newspaper consumption (print) and is lowered in other parts like bookstores, libraries and even performing arts in some cases, we have to look further in new trends like the digital environment and big data. Statistically speaking, in the non-digital environment, culture consumption has a small positive trend, but in the digital environment it is growing 
persistently since 2010 . This new way of interacting and communicating with the consumer opens up more possibilities to target new markets, analyze consumer behavior, establish a unique and personalized marketing mix for any market niche and offer the possibility to give and most importantly, to receive feedback to and from the client. The communication between business and consumer is much much closer now. Consumers are getting more and more savvy and smart in their decisions and this means that companies that offer performing arts and cultural services need to stay close to the consumer in order to answer their needs, surpass their expectations and loyalize them in order to grow their brand awareness.

\section{Conclusion}

Big Data and marketing go hand in hand in 2017. There are many tools that help marketers promote their products and services to specific markets and in some cases, specific users, based on search patterns and needs.

One interesting part about the digital environment is that consumers offer their information and together with machine learning and predictive artificial intelligence, companies can better satisfy their needs. In the world of culture and performing arts this means the opportunity to set new trends and identify new cultural patterns.

Utilizing data obtained from culture consumers could be useful as well in developing special attractions in cities. Amenities can be promoted and programmed with the help of big data and the internet of things (Prakash and Kumar, 2016, p. 22).

Another conclusion is that cultural services can be promoted through the digital environment with the help of a unique and personalized marketing mix. We have seen the way in which individuals interact in real life and on the interest: in most cases there are different mostly because of the lack of human interaction. We can extrapolate and propose the idea that consumers are lacking inhibitions in the digital environment, offering more information about themselves, their preferences and their expectations. This can be used not only in the cultural services industry, but also in all industries.

The performing arts and cultural services companies must offer a unique selling proposition different from pricing models. One way to look at it is to offer consumers emotion, a story that makes them feel like they belong in it and it convinces them that they not only want, but need that companies service.

\section{References}

Arkian, R., Diyanat, A. \& Pourkhalili, A. (2017). MIST: Fog-based data analytics scheme with cost-efficient resource provisioning for IoT crowd sensing applications, Journal of Network and Computer Applications. 82, 154. Retrieved from http://iotiran.com/component/k2/item/download/288_3d490e92eb8fd8a717a644 $\mathrm{fb} 1 \mathrm{ba7bc} 93$.

Barnao, W. (2017), How algorithmic cultural recommendation influence the marketing of cultural collections. Conspumtion Markets \& Culture, 20(6), 559-574. Retrieved from https://doi.org/10.1080/10253866.2017.1331910.

Behnam, R., Arabghalizi, T. \& Brambilla, M. (2017). Analysis of online user behavior for art and culture events. Computer Science, 219-236. Retrieved from DOI 10.1007/978-3319-66808-6_15. 
Blythe, J. (2005), Essentials of Marketing - Third Edition. Essex: Prentice Hall, pp 44-121.

Bowman, M., Krotov, V. \& Alharthi, A. (2017), Addressing barriers to Big Data. Business Horizons, 60(3), 287-290. Retrieved from 10.1016/j.bushor.2017.01.002.

Cejdo, R. \& Rodigruez-Gutierrez, P. (2016), An assessment model for business commitment to culture and fine arts> Application to the Spanish IBsEX 35 listed companies. Emerald Group Publishing Ltd, 181-205. Retrieved from DOI: 10.1108/S1529209620160000016007.

Chaffey, D. \& Ellis-Chadwick, F. (2016), Digital Marketing (6 $6^{\text {th }}$ edition). London: Pearson Education Limited.

Europa Direct (2016), Culture statistics 2016. Luxembourg Publications Office of the European Union, Belgium. Retrieved from http://ec.europa.eu/eurostat/en/web/products-statistical-books/-/KS-04-15-737.

Groene, F. \& Acker, O. (2015), The digital future of creative Europe - The impact of digitization and the internet on the creative industries in Europe. New-York: PwC, 6 - 84. Retrieved from https://www.strategyand.pwc.com/media/file/The-digitalfuture-of-creative-Europe-2015.pdf.

Jimenez, A. \& Gervilla, M. (2011), Manual de marketing y comunicacion cultural. Cadiz: Atalaya Proyecto, 142. Retrieved from http://www.bizkaia.eus/home2/archivos/DPT04/Temas/producto44manual-demarketing-y-comunicacioncultural_web.pdf?hash=2d06bcf005d8249ce3039d3b96b1c077\&idioma=EU.

Kotler, P. (2011). Reinventing Marketing to Manage the Environmental Imperative. Journal of Marketing, 75(4), 132-135. Retrieved from https://doi.org/10.1509/jmkg.75.4.132.

Kotler, P., Armstrong, G., \& Opresnik, O. (2017), Principles of Marketing. Harlow: Pearson, 213.

Keegan, J. \& Green, M. (2017). Global Marketing. Essex: Pearson Education Limited, 493494.

Kelliher, A. (2015). Machines Learning Culture. US: IEEE Computer Society, 22(2), 18-22. Retrieved from DOI: 10.1109/MMUL.2015.43.

Magaudda, P. (2011). When materiality 'bites back`: Digital music consumption practices in the age of dematerialization/ Journal of Consumer Culture, 11(1), 32-34. Retrieved from DOI: $10.1177 / 1469540510390499$.

Moore, P. (2016). Big Data and structural organization in major arts bodies: an evolving ethnographic method. Cultural Trends, 25(2), 104-115. Retrieved from https://doi.org/10.1080/09548963.2016.1170945.

National Institute of Statistics (2017), Activity of Cultural- Artistic Units in 2016.

National Institute of Statistics (2016), Activity of Cultural-Artistic Units 2015.

Ourasang, G. \& Parande, P. (2016). Big Data analytics service framework for advertising and marketing. IJISET, 3(8), 2-4. Retrieved from http://ijiset.com/vol3/v3s8/IJISET_V3_I8_39.pdf

Papadopoulos, S., Cesar, P., Shamma, D. \& Jain, R. (2015), SoMuS: Social Multimedia and Storytelling. IEEE MultiMedia, 22, 1-3. Retrieved from DOI:10.1109/MMUL.2015.68

Prakash, A. \& Kumar, S. (2016). Role of Big Data and Analytics in Smart Cities, IJSR, 1-12. Retrieved from https://www.ijsr.net/archive/v5i2/NOV161007.pdf. 